\title{
O BRASIL, SEUS SÓCIOS E SEUS NEGÓCIOS
}

Luís Antônio Paulino

\begin{abstract}
Resumo: O objetivo é discutir a questão da inserção do Brasil na economia mundial em um novo contexto marcado pelo fenômeno da globalização, pela constituição da Organização Mundial do Comércio - OMC como órgão de governança econômica global e pela proliferação dos blocos regionais de comércio. Palavras-chave: comércio; OMC; Alca; Mercosul; protecionismo.

Abstract: This article considers Brazil's evolving role in a world economy marked by globalization, the creation of the World Trade Organization as an organ of global economic governance, and the proliferation of regional trading blocks.

Key words: trade; WTO; FTAA; Mercosul; protectionism.
\end{abstract}

A discussão, neste artigo, sobre a inserção do Brasil na economia mundial pretende destacar, particularmente, em que medida as novas regras de funcionamento da economia mundial estabelecidas no âmbito da Organização Mundial de Comércio - OMC, bem como as futuras obrigações advindas de uma eventual adesão do Brasil à Área de Livre Comércio das Américas - Alca, condicionam as perspectivas de desenvolvimento do país.

A tese central deste texto é que a adesão do Brasil à $\mathrm{OMC}$, em que pese o interesse do país na manutenção e no fortalecimento de um sistema multilateral de comércio, trouxe, até o momento, mais encargos e obrigações do que benefícios. Do mesmo modo, a adesão do país à Alca, nos termos que os Estados Unidos tentam impor, representará um entrave a mais para o desenvolvimento social e econômico do Brasil.

Este artigo está dividido em cinco partes: na primeira, se analisa a nova dinâmica da economia global, destacando-se particularmente o papel das empresas multinacionais nesse novo contexto; na segunda, discute-se o papel da OMC como fiadora da nova ordem global; na terceira, faz-se uma breve análise da inserção do Brasil na nova divisão internacional do trabalho que se consolida sob a égide dessa nossa "Cons- tituição" da economia mundial estabelecida no âmbito da OMC; na quarta, são abordados os mecanismos internos e externos por meio dos quais as assimetrias nas relações internacionais, geradas a partir dessa nova ordem, tendem a se aprofundar; e, finalmente, na quinta parte, se analisa brevemente o conjunto de negociações comerciais atualmente em curso das quais o Brasil participa e que opções se colocam para o país no esforço de alcançar uma inserção internacional mais vantajosa no contexto analisado.

\section{A NOVA DINÂMICA DA ECONOMIA GLOBAL}

O principal fenômeno que marca a etapa atual da economia mundial é o da globalização, processo através do qual os fluxos comerciais, financeiros e produtivos ocorrem num plano que, até certo ponto, elidem as fronteiras nacionais e, portanto, os mecanismos tradicionais de controle dos Estados nacionais sobre a atividade econômica em seus territórios.

Os principais agentes deste processo são as empresas multinacionais, que respondem por aproximadamente um terço de toda a produção e por $60 \%$ das exportações mundiais, sendo que metade desse fluxo ocorre interfirmas, 
ou seja, entre diferentes unidades de uma mesma empresa. Esse verdadeiro exército de ocupação da economia mundial é composto por cerca de 40 mil empresas e 250 mil filiais espalhadas pelo mundo. O total de ativos das filiais estrangeiras correspondia, em 1999, a um valor equivalente a $60 \%$ do PIB mundial, bem acima dos $27 \%$ do começo dos anos 90 e dos $18 \%$ do início dos 80 .

Se as multinacionais são os agentes principais do processo de globalização, o investimento direto estrangeiro é o combustível que alimenta essa rede que ocupa a economia mundial. Esses fluxos, que em 1985 eram de US\$ 50 bilhões, saltaram, em 1990, para US\$ 200 bilhões, em 1999 já eram US\$ 800 bilhões e, no final do ano 2000, correspondiam a cerca de US\$1,3 trilhão (Lacerda, 17/05/01).

$\mathrm{O}$ investimento direto estrangeiro, por sua vez, ocorre através de diferentes modalidades, das quais as mais freqüentes, hoje, têm sido as aquisições, fusões e privatizações. As razões para isso estão no baixo crescimento da economia mundial, o que abre mais espaço para transações de permuta e transferência de propriedade de capital do que propriamente de criação de nova riqueza.

O Brasil tem se destacado nos últimos anos pela atração de investimento direto estrangeiro, figurando, entre os países em desenvolvimento, apenas atrás da China. Em 1990, o Brasil recebeu US\$ 1 bilhão em investimento direto estrangeiro, em 1998 este montante havia saltado para US\$ 30 bilhões e, entre 1998 e 2000, a média anual foi de US\$ 31,1 bilhões anuais, volume seis vezes maior que a média registrada no período 1970 a 2000 . Os setores produtivos que hoje atraem o capital estrangeiro no Brasil também são outros. A participação da indústria no estoque de investimentos diminuiu de 45,2\%, em 1995, para $11,2 \%$ no total acumulado entre 1998 e 2000 , enquanto a do setor de serviços saltou de $37,3 \%$ para $76,3 \%$, no mesmo período. As fusões e aquisições chegaram a represen$\operatorname{tar} 89,9 \%$ do montante de recursos que entraram no país, em 1998. Os setores de telecomunicações e de intermediação financeira foram mais atraentes às aquisições por parte de capitais estrangeiros, representando, juntos, 37,8\% dos investimentos estrangeiros diretos acumulados entre 1998 e 2000 (Castro, 15 a 21/10/01).

Para o ano de 2001, é provável que esses fluxos de investimento direto estrangeiro apresentem uma redução expressiva. A Conferência das Nações Unidas para o Comércio e Desenvolvimento (Unctad) divulgou recentemente o "World Investment Report" para 2001, apontando uma queda de $40 \%$ no fluxo global de investimentos estrangeiros para este ano (Lacerda, 05/10/01).
A redução nesses fluxos está relacionada com a tendência recessiva da economia mundial que já vinha se desenhando desde meados de 2000 e que poderá ser agravada em função do ataque terrorista nos Estados Unidos, em 11 de setembro de 2001, cujos desdobramentos no plano econômico mundial ainda não estão inteiramente claros. Considerando-se, entretanto, que uma questão fundamental a condicionar as decisões de gasto e investimento é o estado de confiança dos consumidores e investidores com relação ao futuro, é de se esperar que as tendências recessivas que já se esboçavam serão agravadas ainda mais pelo grau de incerteza gerado pelos conflitos.

\section{O PAPEL DA OMC}

A nova dinâmica da economia global exige, no plano institucional, um ambiente cada vez mais desregulado, que permita e garanta o livre fluxo de capitais e mercadorias de acordo com a estratégia global dos grandes grupos que dominam a economia mundial. A reivindicação mais freqüente dos representantes das grandes corporações multinacionais nos inúmeros fóruns internacionais convocados para debater o tema expressa-se amiúde pelo termo "nivelar o campo de competição".

A existência de diferentes normas e regulamentos na área comercial, financeira, tributária, trabalhista e no regime de proteção à propriedade intelectual nos diversos países em que atuam, bem como a possibilidade que cada país possui de mudar as regras do jogo de acordo com as suas próprias conveniências e circunstâncias, constitui-se, para essas empresas, em elemento que aumenta o grau de incerteza normalmente associado às decisões de investimento (Marques Jr., 30/10/01).

Considerando-se que, de algum modo, todo o planejamento estratégico dessas grandes multinacionais está circunscrito por um triângulo em cujos vértices podem ser colocados, respectivamente, os objetivos da empresa, a governança e a governabilidade, é de se imaginar que a capacidade de organizar suas competências em função dos objetivos a atingir (governança) está fortemente condicionada pela governabilidade, isto é, pela capacidade de controlar as diversas regras e fluxos que condicionam suas jogadas estratégicas.

Desse ponto de vista, a existência de regras e fluxos fora do campo de controle dessas empresas constitui uma situação percebida como problemática e evitável. A reivindicação de nivelar o campo de competição, por meio da padronização das regras no âmbito da OMC, torna-se, 
assim, a reivindicação mais relevante dos grandes atores econômicos globais.

Há, contudo, entre a taça e os lábios, inúmeros percalços. Da mesma forma que outras situações ideais prescritas pelo ideário liberal, como a livre concorrência, a tendência ao equilíbrio e o comportamento racional dos agentes econômicos, o nivelamento do campo de competição reflete um desejo cujas condições objetivas de realização dificilmente encontram-se na realidade.

As razões para isso são inúmeras. Aponta-se freqüentemente a resistência dos países em desenvolvimento de abrirem seus mercados e adotarem regras estáveis no tratamento do capital estrangeiro. A verdade, no entanto, parece ter várias faces e cada um vê a que mais lhe convém. Enquanto os países em desenvolvimento vêm dando grandes passos no processo de abertura comercial e adaptação de suas regras econômicas aos padrões reivindicados pelas multinacionais, as nações desenvolvidas aceitam a padronização das regras desde que sejam as suas regras e nem mesmo se entendem entre si, como ficou patente na malograda tentativa de lançamento de uma nova rodada de discussões da Organização Mundial do Comércio - OMC, a que seria a Rodada do Milênio, em Seattle, em 1999.

No entanto, por mais imperfeito que seja, esse novo campo de competição encontra-se muito menos obstruído do que há alguns anos, pelo menos no que diz respeito aos países em desenvolvimento, que foram obrigados a abandonar uma série de mecanismos de proteção a suas indústrias e produtores locais e abrir seus mercados à competição internacional.

Já os países desenvolvidos, escudados no argumento de que suas economias já eram bastante abertas aos fluxos internacionais de mercadorias e capitais, pouco tiveram de ceder para obter enormes concessões dos países em desenvolvimento. Além disso, naquilo que se comprometeram a ceder, pouco fizeram de concreto. Tome-se, por exemplo, o Acordo de Têxteis e Vestuários celebrados na OMC, em 1994, segundo o qual os países desenvolvidos se comprometeram a eliminar gradualmente todas a cotas que restringem as exportações dos países em desenvolvimento em cerca de US\$ 350 bilhões ao ano, até sua extinção completa em 31 de dezembro de 2004. Até agora, passados sete anos da assinatura do acordo, $80 \%$ das cotas ainda estão vigendo. De 757 cotas, os EUA aboliram apenas 56, a UE apenas 52 de 219 e o Canadá não mais que 54 de 295 (Moreira, 01/11/01).

Embora pelas regras da OMC cada país teoricamente tenha um voto e cada voto tenha o mesmo peso, na prática quem comanda o processo são as grandes potências comerciais. União Européia, Estados Unidos e Japão respondem por $60 \%$ das importações mundiais e suas empresas e consumidores gastam mais de US\$ 3 trilhões anuais em produtos vindos do exterior. A história tem mostrado que, seja na vigência do antigo Gatt, seja com a OMC, as regras de comércio mundial são ditadas por quem controla o acesso aos principais mercados e os demais países as aceitam porque não podem deixar de fazê-lo (Moreira, 29/08/01).

Tome-se, por exemplo, a declaração ministerial preparada pelo presidente do conselho geral da OMC, Stuart Harbinson, para lançar, no Catar, em novembro de 2001, uma nova rodada global de negociações globais. Ela reflete de fato quem manda na OMC, uma vez que leva em conta pelo menos $80 \%$ das propostas apresentadas pelos Estados Unidos, $60 \%$ daquelas encaminhadas pela União Européia e apenas $15 \%$ do que foi proposto pelo resto do mundo (Moreira, 01/11/01).

Destaque-se, ainda, que diferentemente dos acordos sobre comércio internacional celebrados no âmbito do GATT (General Agreement on Tariffs and Trande - Acordo Geral sobre Tarifas e Comércio), a Rodada Uruguai (1986-1994), que culminou com a criação da Organização Mundial do Comércio - OMC, logrou colocar sob sua égide os mais diversos problemas econômicos contemporâneos. Nas palavras de Renato Ruggiero, primeiro-diretor geral da OMC, a Organização Mundial do Comércio "é a Constituição de uma única economia global" (Folha de S.Paulo, 07/07/97). Através do uso da expressão “comércio e..." em todos os acordos celebrados, os mais diversos problemas econômicos internacionais da atualidade, como propriedade intelectual, investimentos, serviços, etc., foram colocados sob seu controle.

A criação da $\mathrm{OMC}$ representou, assim, um avanço em termos de relações econômicas internacionais do que se convencionou a chamar de "integração rasa" para a "integração profunda". Essa mudança de enfoque significou que, antes da $\mathrm{OMC}$, os regimes regulatórios nacionais eram um dado a partir do qual se discutia a liberação comercial; com a OMC o que entra em discussão são os próprios regimes regulatórios nacionais.

\section{INSERÇÃO DO BRASIL NA NOVA DIVISÃO INTERNACIONAL DO TRABALHO}

Esse processo de globalização da economia, resumidamente descrito até aqui, tem como conseqüência imediata a configuração de uma divisão internacional do tra- 
balho que, de certo modo, leva às últimas conseqüências o preceito bíblico segundo o qual "aos que tudo têm, tudo será dado, e aos que nada têm, tudo será tirado".

Tal fato ocorre, entre outros motivos, porque o processo de globalização, ao encurtar a dimensão espaço-tempo dos fluxos internacionais de produção, comércio e capital, exige uma eficiência muito maior dos participantes desse jogo e expõe de maneira muito mais aguda a sua fragilidade estrutural, não mais protegida pelas barreiras políticas e institucionais que caracterizam o jogo econômico mediado pelo Estado.

Nessas novas condições, as relações internacionais de troca do Brasil e outros países em desenvolvimento na mesma condição, particularmente da América Latina, deterioram-se nos últimos anos. O Brasil exporta um volume cada vez maior de mercadorias e obtém pela sua venda no mercado internacional um montante cada vez mais reduzido de recursos. Veja-se o caso do café: nos primeiros nove meses de 2001, as vendas brasileiras de café verde para o exterior chegaram a 14,3 milhões de sacas de 60 quilos, que representam um acréscimo de $26 \%$ em relação ao mesmo período de 2000 , porém a receita em dólares foi $22,6 \%$ menor do que a anterior (Carvalho, 01/11/01).

Exportam-se mercadorias com cada vez menos valor agregado e importam-se produtos cada vez mais sofisticados. Enquanto o agrobusiness brasileiro gera um superávit comercial de US\$ 11 bilhões anuais, setores de ponta como o eletroeletrônico, máquinas e equipamentos mecânicos e químico perfazem um déficit acumulado de US\$ 15 bilhões ao ano (Lacerda, 18/06/01).

Segundo pesquisa realizada conjuntamente entre o Instituto Brasileiro de Economia (Ibre), a Fundação Getúlio Vargas (FGV-RJ) e a Sociedade Brasileira de Estudos de Empresas Transnacionais e da Globalização Econômica (Sobeet), envolvendo importações e exportações de tecnologia entre 1990 e 2000, no acumulado desses 11 anos, entendendo-se como tecnologia um rol variado de componentes produtivos, que vai do fornecimento direto de tecnologia industrial a licenças pelo uso de patentes, passando por serviços de assistência técnica e implantação de projetos, o Brasil exportou menos de US\$ 3 bilhões e comprou no exterior cerca de US\$ 11,5 bilhões (Kupfer, 17/10/01).

A importação de componentes para a indústria de telecomunicações superou, nos últimos quatro anos, a compra externa de derivados de petróleo. O crescimento das empresas de telefonia fez com que o déficit comercial no setor chegasse, em 2000, a U\$ 6,4 bilhões. No mesmo período, o saldo negativo da indústria de petróleo foi de US\$ 4,8 bilhões (Magnavita, 19/06/01).

Segundo estudo do Instituto de Estudos do Desenvolvimento Industrial - Iedi, apenas $18 \%$ das exportações brasileiras representam uma combinação considerada ótima, ou seja, são feitas por setores nos quais o país ganhou competitividade e que, simultaneamente, apresentam demanda crescente no comércio mundial. Segundo o referido estudo, "os setores nos quais o Brasil apresenta vantagem comparativa representam uma parcela muito menor (e decrescente) do comércio mundial (...) o que significa que o comércio mundial está mais voltado para produtos em que o Brasil não desenvolveu vantagem comparativa" (Rossi, 03/06/01).

Entre $60 \%$ e $65 \%$ das exportações brasileiras são de mercadorias básicas (commodities), produtos vendidos em grandes quantidades, sem qualidade diferenciada. Seu preço oscila muito, dependendo do ritmo de produção e consumo internacionais. Depois dos atentados de 11 de setembro ao World Trade Center, por exemplo, o preço do petróleo caiu $20 \%$ com expectativa de retração da economia mundial. O Brasil foi beneficiado pela redução do preço do óleo, mas saiu perdendo no aço, alumínio, papel, celulose, café, soja, suco de laranja e outros produtos agrícolas. Em 18 meses, o preço do aço caiu 30\%. A cotação do alumínio está num dos níveis mais baixos dos últimos dez anos. Desde 1957, o café não custava tão pouco. Os preços agrícolas brasileiros atingiram, em outubro de 2001, a cotação mais baixa em mais de uma década, com exceção de três meses em 1992 e 1993 (Grinbaum, 21/10/01). Ilustrativo dessa deterioração dos termos de troca é o fato de que, se os preços dessas commodities estivessem nos mesmos níveis de 1997, as exportações brasileiras de 2001, que deveriam alcançar US\$ 58 bilhões, poderiam render US\$ 69 bilhões, ou seja, US\$ 11 bilhões a mais.

Um outro fato que deve ser lembrado para demonstrar a fragilidade da inserção brasileira nos fluxos internacionais de comércio é a alta concentração das exportações em alguns poucos produtos, para uns poucos países e em poucas empresas e Estados brasileiros. Segundo a Agência de Promoção de Exportações (Apex), dez itens representam $35 \%$ de nossa pauta de exportação, dez países absorvem $66 \%$ do total exportado pelo Brasil, 97 grupos empresariais são responsáveis por $53 \%$ do comércio externo nacional e os Estados das regiões Sul e Sudeste detêm 80\% das vendas externas brasileiras (Prado, 09/07/01).

A bem da verdade, essa crescente fragilidade da inserção comercial do Brasil não é resultado do nivelamento 
do campo de competição, mas sim do nivelamento da via de entrada de produtos e serviços nos países em desenvolvimento e da permanência de entraves e entulhos que se acumulam cada vez mais nas vias de saída.

O empobrecimento da pauta de exportação dos países em desenvolvimento como o Brasil não se deve apenas ao fato de nossas empresas serem obrigadas a competir em pé de igualdade com concorrentes com poder tecnológico, econômico e financeiro muito maior. Os países que dominam o comércio internacional e comandam o acesso aos principais mercados promovem uma abertura seletiva de seus mercados. Baixam ou mesmo eliminam tarifas e barreiras não tarifárias para produtos nos quais os países em desenvolvimento não têm condições de competir ou que não sejam politicamente sensíveis em seus países ou ainda que não tenham interesse ou condições de produzir, principalmente matérias-primas e insumos intensivos no uso de energia ou que exijam processos de produção altamente poluidores. Impõem, contudo, barreiras elevadas para produtos mais elaborados que possam concorrer com sua produção local, principalmente nos setores politicamente mais sensíveis, como a agricultura, nas indústrias decadentes e pouco competitivas mas com grande força política, como a siderúrgica, ou ainda naqueles segmentos que utilizam intensivamente mão-de-obra, como o setor têxtil.

Segundo estudo de Marta Reis Castilho, a média ponderada das tarifas aplicadas pela UE aos exportadores do Mercosul que se concentram em "produtos sensíveis" aumenta de forma expressiva em relação à média geral de tarifas. No caso de produtos alimentícios, essa média sobe de $8,4 \%$ para $32 \%$ e, para os produtos agrícolas, de $7,5 \%$ para $15,6 \%$. O mesmo raciocínio é valido para as chamadas barreiras não-tarifárias. Do total das exportações do Mercosul para a UE, cerca de $23 \%$ estão sujeitas a algum tipo de restrição. Esse percentual, entretanto, sobe para $87,9 \%$ no caso de produtos alimentícios, para $98 \%$ em pele, couros e seus artigos e para $63,9 \%$ em ferro e aço (Canuto, 16/10/01).

A evolução das exportações brasileiras no complexo da soja revela de forma exemplar a degradação da nossa pauta de exportações em função da escalada tributária, processo através do qual os países ricos taxam com alíquotas mais elevadas os produtos de maior valor agregado, enquanto liberam seus mercados para importação de matérias-primas que não produzem.

O Brasil já foi o principal exportador mundial de óleo e de farelo de soja, superando os EUA, principal produtor e consumidor mundial. Há cinco anos tínhamos capa- cidade de esmagamento de 33 milhões de toneladas/ano de soja em grão e industrializamos 21,6 milhões de toneladas, diante de uma safra de 26 milhões de toneladas. Mesmo com um crescimento da safra de soja da ordem de $46 \%$ nesse período, a capacidade de esmagamento caiu $15 \%$ e continuamos esmagando os mesmos 21,6 milhões de toneladas, evidenciando um processo de desindustrialização na agroindústria (Magalhães, 05/09/91).

A causa disso está no fato de que, enquanto a soja em grão paga taxas de importação relativamente modestas, os derivados da soja de maior valor agregado pagam taxas muito superiores à média. No mercado dos Estados Unidos, por exemplo, o óleo de soja é taxado em 19,1\%, muito superior à tarifa média americana de $3 \%$ a $4 \%$. A China recorre a um sistema de cotas tarifárias para barrar a importação de óleo e soja e aplica uma tarifa de $122 \%$ às importações extra-cota. A cotas não são liberadas e, assim, o óleo é taxado em $122 \%$. Simultaneamente, a China importa montanhas de matéria-prima com uma tarifa de apenas $3 \%$. A Índia, a maior importadora de óleos vegetais, elevou a tarifa de importação três vezes nos últimos 12 meses (Maggi, Lovatelli e Rodrigues, 11/06/01).

$\mathrm{O}$ caso do café não é menos exemplar. O Brasil exporta principalmente café verde, que é processado nos países de destino. Em 2000, dos 18 milhões de sacas exportadas, 16 milhões foram dessa variedade (Carvalho, 01/11/ 01). A Alemanha, por exemplo, apesar de não plantar um único pé de café, já é o terceiro exportador mundial do produto. Para conseguir tal façanha, libera a importação de grãos, que não produz, e, por meio de tarifas e outras barreiras não-tarifárias, dificulta a importação do café solúvel, de maior valor agregado. ${ }^{1}$ Desta forma, um saco de café verde importado a US\$ 60 pode gerar para a economia local uma renda dezenas de vezes superior. Segundo o economista inglês Jan Kregel, enquanto o Brasil ganha US\$ 1 por quilo de café, a Alemanha, ao beneficiá-lo e vendê-lo no mercado europeu, ganha US\$ 12 por quilo (Steinbruch, 30/10/01).

O que ocorre com o couro não é muito diferente. O Brasil é grande produtor mundial de couro bovino, uma matériaprima muito valorizada no mercado internacional. Cada animal abatido fornece uma peça de couro suficiente para a produção de aproximadamente 25 sapatos. É mais interessante e lucrativo exportar couro acabado ou calçado do que exportar couro cru ou semi-acabado. Para se ter uma idéia das diferenças, basta saber que uma peça de couro cru custa cerca de US\$ 10 no mercado internacional, enquanto, a peça de "wet blue", um couro semi-elaborado, 
sai por US\$ 30 . A peça do "crust", um pouco mais elaborado, custa US\$ 60 e a do couro acabado, US\$70. Já os 25 pares de calçados que podem ser feitos com essa peça de couro valem US\$350, em média. Acontece que, nos últimos tempos, tem aumentado muito a exportação brasileira do "wet blue", fazendo com que, em vez de se exportarem calçados que renderiam US\$ 350 por boi abatido e gerariam milhares de empregos no Brasil, exporta-se cada vez mais o couro semi-elaborado, a US $\$ 30$ por peça. Isso ocorre porque a União Européia aplica uma taxa de 17\% sobre os calçados importados e de 6,5\% sobre o couro acabado. O "wet blue", porém, entra na comunidade européia sem nenhuma taxação. Estima-se que o Brasil estaria deixando de receber divisas de pelo menos US\$ 400 milhões anuais por causa dessa exportação de couro semi-acabado no lugar do produto acabado (Steinbruch, 11/07/00).

$\mathrm{O}$ resultado dessa inserção assimétrica da economia brasileira no comércio mundial são a fragilidade e a vulnerabilidade crescentes do país em uma conjuntura internacional cada vez mais volátil.

A fragilidade externa da economia brasileira tem sido ainda agravada pela desnacionalização das empresas, que implica crescentes remessas de lucros, além do pagamentos de juros, royalties, etc., o que provoca uma rigidez na conta de serviço em cerca de US\$ 25 bilhões/ano.

Acrescente-se ainda que a maior parte do investimento direto estrangeiro que tem ingressado no país destina-se à produção de mercadorias e serviços voltados para o atendimento do mercado interno e não para exportação. Como observado anteriormente, a participação da indústria no estoque de investimentos diminuiu de 45,2\%, em 1995, para $11,2 \%$ no total acumulado entre 1998 e 2000 , enquanto a do setor de serviços, voltado essencialmente para o mercado interno, saltou de $37,3 \%$ para $76,3 \%$, no mesmo período (Castro, 15 a 21/10/01).

\section{RELAÇÕES ASSIMÉTRICAS}

As assimetrias nas relações de comércio do Brasil com os países desenvolvidos têm raízes profundas fincadas em diferentes terrenos, sendo muitas delas em solo pátrio, resultado de nossa própria estratégia industrial e de comércio exterior. A especialização produtiva do Brasil na produção de commodities e produtos de menor valor agregado não é propriamente uma imposição externa, muito embora o fenômeno da escalada tributária e outras medidas protecionistas dos países desenvolvidos contribuam significativamente para isso.
Trata-se, em última instância, de uma opção política e econômica do próprio país. Enquanto no século XIX, os Estados Unidos, inspirados no pensamento nacionalista e antiliberal de Alexander Hamilton adotavam políticas protecionistas em defesa de sua própria indústria nascente, no Brasil, as idéias liberais e livre-cambistas de Adam Smith faziam sucesso entre a elite agrária exportadora, divulgadas em primeira-mão pelo Visconde de Cairu. Idéias que preconizam para o Brasil a condição de um país agrário, especializado na exportação de produtos agrícolas, sempre encontraram guarida entre as elites conservadoras brasileiras e foram decisivas na formulação de nossa estratégia de desenvolvimento. Prova disso são a ferrenha oposição enfrentada dentro e fora do governo pelos pioneiros da industrialização no Brasil (Irineu Evangelista de Souza, o Barão de Mauá, Roberto Simonsen, Delmiro Gouveia, entre outros) e a famosa polêmica que se travou, em 1944, entre Roberto Simonsen e Eugênio Gudin, patrono dos liberais brasileiros, a propósito da vocação agrária ou industrial do país (Draibe, 1985). Tais polêmicas, ainda que revestidas de novas roupagens, perduram até os dias de hoje, como revela o debate recente entre as correntes liberal-desenvolvimentista e neoliberal dentro do governo do presidente Fernando Henrique Cardoso.

O desempenho exportador da Embraer que, ao lado da canadense Bombardier, é um dos dois mais importantes fabricante mundiais de jatos comerciais de médio porte, mostra que, quando se produzem mercadorias de alto valor agregado e demanda crescente no mercado mundial, as dificuldades criadas pelas políticas protecionistas de outros países têm um peso relativamente menor em nossa capacidade de exportar, o que não quer dizer, naturalmente, que não existam, haja vista as manobras do governo do Canadá para impedir o avanço da empresa brasileira no mercado mundial.

A pequena reação das exportações brasileiras mesmo com a desvalorização cambial de janeiro de 1999 mostra que a concorrência via preços no mercado mundial, para um grande número de produtos, está em segundo plano. Para produtos mais sofisticados, de alto conteúdo tecnológico, o elemento central na concorrência não é o preço. Nas mercadorias cujo preço é o fator mais relevante - o que ocorre basicamente no mercado de commodities, no qual o Brasil especializou-se -, as barreiras tarifárias e não-tarifárias são utilizadas de forma intensiva, para proteção dos produtores locais dos países desenvolvidos, de modo que pouco resolve ser competitivo.

Tome-se, como exemplo, o açúcar. No Brasil, a produção de uma tonelada de açúcar tem um custo de US\$ 
180. O produtor dos Estados Unidos gasta duas vezes e meia mais que o brasileiro, investindo US $\$ 450$ para produzir uma tonelada de açúcar a partir da beterraba. Já o custo de produção na Europa é 394\% superior ao brasileiro - a tonelada de açúcar produzido a partir da beterraba pelos europeus não sai por menos de US\$ 710. Diante de tão gritante diferença de custos, seria de se esperar que o açúcar brasileiro tivesse entrada franqueada naqueles mercados. Não é, entretanto, o que ocorre. O acesso do produto nacional é constrangido, quando não inviabilizado, por uma pesada política protecionista, que envolve desde barreiras tarifárias até rígidos sistemas de cotas. Os Estados Unidos, por exemplo, precisaram importar, em 2001, mais de 1,2 milhão de toneladas para cobrir suas necessidades de consumo. As importações de açúcar brasileiro, porém, estão limitadas a uma cota de insignificantes 152 mil toneladas. Para ingressar no mercado europeu, o açúcar brasileiro paga uma taxa de US\$ 367,67 a tonelada, o que representa um ágio de $63 \%$ em relação aos preços internacionais de uma tonelada de açúcar, situados em US\$ 225 (Gazeta Mercantil, 13/08/01).

Nos 50 anos decorridos desde a criação do Gatt, cujo propósito era o de liberalizar os fluxos de comércio internacional praticamente interrompidos durante a Segunda Guerra Mundial, as tarifas de importação dos bens industriais caíram de uma média de $40 \%$ para os atuais $2 \%$. Para produtos agrícolas, entretanto, as restrições não só não caíram na mesma proporção como, pelo contrário, em inúmeros casos aumentaram, inclusive depois da criação da OMC (Rossi, 21/10/01).

Um dos fatores restritivos para o aumento de nossas exportações encontra-se no fato de que cada vez mais nos especializamos na produção de mercadorias que o mundo não quer comprar, ou melhor dizendo, cuja demanda é altamente inelástica com relação tanto ao preço quanto à renda. Nisso concordam analistas internos e externos. Jeffrey Sachs, proeminente economista de Harvard, em entrevista recente a uma revista brasileira, foi enfático: "O Brasil precisa urgentemente de uma estratégia de crescimento baseada em tecnologia. O país deve investir mais em pesquisa e desenvolvimento, em universidades e na atração de empresas de alta tecnologia, como as de semicondutores (...) O Brasil precisa exportar para atingir a prosperidade. Não vendendo produtos agrícolas, mas, sim, de alta tecnologia. Se isso fosse feito, o país poderia realmente dar um grande salto" (Salgado, 18/07/01). Eugênio Staub, empresário nacional do setor eletroeletrônico, presidente do Instituto de Estudos do Desenvolvimento
Industrial - Iedi, vai na mesma direção: "O problema é basicamente o seguinte: $\mathrm{O}$ Brasil não está produzindo o que o mundo quer comprar" (Racy e Oliveira, 02/09/01).

Independentemente dos equívocos de política interna, as assimetrias existentes nas relações internacionais de troca do Brasil com o resto do mundo são decorrência do desenvolvimento desigual do capitalismo mundial, em que os que estão sentados à mesa tentam a todo custo impedir a chegada de novos comensais, quando muito atirandolhes algumas migalhas. E o fato concreto é que a OMC pouco ou nada fez até agora para alterar esse status quo. Ao contrário, sua ação mais parece orientar-se na direção de mantê-lo ad infinitum. O mesmo parece ser o sentido que os Estados Unidos tentam imprimir à futura Alca, caso não encontrem maiores resistências dos demais parceiros.

A prova de que tal suspeita não é infundada está na quase total incapacidade da OMC de impedir que as economias desenvolvidas tomem as mais variadas medidas protecionistas para defender seus mercados e, ao contrário, na presteza com que agem contra os supostos desvios dos países em desenvolvimento quando estes supostamente fogem das regras acordadas. Ou ainda na tentativa de impor como padrão mundial normas acordadas no âmbito da OCDE, que congrega apenas os países desenvolvidos, como ocorreu recentemente em relação às regras de financiamento às exportações, que obrigaram o Brasil a modificar as regras do Proex, principalmente o mecanismo de financiamento que a Embraer vinha utilizando para exportar aviões, e adaptá-la aos padrões dos países desenvolvidos, quando se sabe que as condições de disponibilidade de capitais é totalmente diferente aqui e acolá.

Isso é mostrado de forma cristalina no relatório anual sobre "Barreiras aos Produtos e Serviços Brasileiros no Mercado Norte-Americano", preparado pela embaixada brasileira em Washington. Segundo editorial do jornal $O$ Estado de S.Paulo (05/10/01), a respeito do referido relatório, "a afirmação, exaustivamente repetida, de que a economia americana é uma das mais abertas do mundo, com tarifas muito baixas, não serve para descrever o comércio com o Brasil. A média tarifária ou de equivalente tarifário, imposta aos 15 principais produtos brasileiros é de 45,6\%, segundo levantamento da embaixada. Quando se consideram os produtos de maior peso na pauta, a economia brasileira é de fato mais aberta: a tarifa média aplicada no Brasil aos 15 principais produtos americanos é de $14,3 \%$, segundo o mesmo estudo".

Note-se, ainda, que tais barreiras, no caso norte-americano, valem tanto para produtos agrícolas como para in- 
dustrializados. A área siderúrgica, por exemplo, é uma das mais afetadas. De um consumo total de 119 milhões de toneladas/ano de produtos siderúrgicos, os EUA importam 18 milhões de toneladas, o que eqüivale a $15 \%$ do consumo total. Do Brasil, os Estados Unidos importam apenas 3 milhões de toneladas/ano ou 2,5\% do seu consumo. Essa participação limitada da produção brasileira no mercado norte-americano, em que pese a alta competitividade da siderurgia nacional, deve-se ao protecionismo crescente do governo dos Estados Unidos, que se traduz em acusações infundadas de dumping e recorrente aplicação de penalidades cujo único objetivo é proteger a indústria norte-americana do aço. Diante de novas demandas de proteção por parte da indústria norte-americana, o governo Bush demandou à Comissão Internacional de Comércio (ITC), comissão do governo norte-americano encarregada de analisar questões comerciais, um novo estudo sobre eventuais danos causados ao setor por concorrentes estrangeiros. Divulgado em 22 de outubro de 2001, o estudo conclui que 12 dos 33 produtos siderúrgicos que o país compra do resto do mundo são subsidiados e sofrerão novas sobretaxas nos próximos meses (Vargas, 23/10/01). A decisão dos EUA de ampliar o protecionismo à indústria do aço provocou a ira de países exportadores em todo mundo, uma vez que se sabe que seu único objetivo é proteger uma indústria sucateada e sem condições de competir com empresas mais modernas e competitivas localizadas não só no Brasil como em outros países em desenvolvimento. Cada tonelada de bobinas laminadas a quente produzida pelas siderúrgicas norte-americanas tem um custo médio de US\$ 260 , enquanto o custo médio internacional é de US\$ 180 (Steinbruch, 30/10/01).

O protecionismo americano não se limita, contudo, ao aço. O açúcar já mencionado anteriormente paga US\$ 338,70 por tonelada extra-cota, o tabaco, $350 \%$, o etanol, $2,5 \%$ mais US\$ 0,52 por galão, o suco de laranja, US\$ 0,785 por litro, e os produtos têxteis $38 \%$ ad valorem, mais US\$ 0,485 por quilo (Nassif, 05/10/01).

O governo americano aumentou, na década de 90 , em quase $400 \%$ os subsídios concedidos aos produtores rurais dos Estados Unidos. Entre 1990 e 2000, a conta total de subsídios agrícola nos Estados Unidos aumentou de US\$ 6,5 bilhões para US\$ 32,3 bilhões ao ano (Romero, 23/ 05/01). Em 26 de junho de 2001, a Câmara dos Deputados dos Estados Unidos aprovou lei que prevê mais US\$ 5,5 bilhões ao ano de auxílio aos produtores por causa da depressão no preço das commodities. A lei prevê US \$ 4,6 bilhões em pagamentos para os produtores de grãos e ou- tros 900 milhões para produtores de outras culturas, como amendoim, hortifrutícolas e tabaco (O Estado de S.Paulo, $24 / 10 / 01)$. A nova lei agrícola substituirá a lei aprovada em 1996 e cuja vigência vai até setembro de 2002. Ignorando o fato de que recentemente o Congresso americano aprovou duas leis assegurando repasse médio anual à agricultura de US\$ 17,5 bilhões para o período entre $2001 \mathrm{e}$ 2011, o projeto da nova lei agrícola agregará ainda mais recursos para o setor. Apenas em novos programas de garantia de preço e renda ao produtor, a lei reserva US\$ 50 bilhões para os próximos dez anos. Só na produção de soja, a ajuda do governo norte-americano passou de US\$ 109 milhões, em 1992, para US\$3,8 bilhões no final dos anos 90 , mais da metade de todo o valor arrecadado com as exportações brasileiras do produto. Como resultado, a produção americana de soja cresceu $30 \%$ (Chade, 24/07/ $01)$. O produtor de algodão americano recebe um subsídio de US\$ 1.144,60 por tonelada, totalizando mais US\$ 4 bilhões por ano (Maggi, 01/11/01).

A questão não se restringe, contudo, aos Estados Unidos. A própria OMC reconheceu no relatório divulgado no final de 2000 que as práticas protecionistas dos países desenvolvidos, especialmente na agricultura, estão aumentando. Segundo o relatório, o apoio dos países desenvolvidos à agricultura havia crescido 5,6\% entre 1999 e 2000, atingindo o nível existente há uma década, quando a Rodada Uruguai estava em negociação. Segundo o relatório, a União Européia teria concedido $45 \%$ do total de subsídios aos agricultores, o Japão, 23\% e os EUA, $21 \%$ (Abbott, 24/11/00). Para o conjunto dos países industrializados, os subsídios são da ordem de US\$ 365 bilhões anuais (Gazeta Mercantil, 23/05/01).

Estudo da própria OMC mostra que as cotas, outro mecanismo de restrição de acesso aos mercados dos países desenvolvidos, aumentaram, ao invés de diminuir, como se poderia esperar da liberalização, ainda que tímida, acertada na Rodada Uruguai. A União Européia (UE) pratica 85 cotas, seguida pelos Estados Unidos (54) e Canadá (21), enquanto o Brasil adota apenas uma, sobre ingresso de pêras e maçãs (Gazeta Mercantil, 23/05/01).

As assimetrias nas relações internacionais de comércio revelam-se ainda em outros terrenos, como na aplicação discricionária da legislação antidumping, principalmente por parte dos Estados Unidos, para proteger sua indústria local, cujo caso mais recente é a nova investida do governo Bush para proteger a indústria local de aço.

Nos anos 90, desde o início da vigência das decisões da Rodada Uruguai que resultou na criação da OMC, os 
recursos dos países às medidas antidumping explodiram: foram registrados 37 casos, em 1995, e 1.218, entre 1995 e 1999 , dos quais $49 \%$ foram aplicados pelos países ricos contra os países em desenvolvimento.

Nos Estados Unidos, o Anti-Dumping Act de 1916, ainda em vigor, viola os compromissos comerciais assumidos por Washington junto à $\mathrm{OMC}$. Essa lei permite às próprias companhias - e não só aos governos, como define o acordo da OMC - abrir processos em tribunais americanos contra importadores e produtores suspeitos de vender seus produtos a preços anormalmente baixos no mercado norte-americano (Moreira, 31/05/01). Qualquer empresa que se sinta prejudicada pode solicitar ao ITC - Comissão de Comércio Internacional -, uma espécie de tribunal que tem a palavra final sobre denúncias de más práticas comerciais, como dumping e subsídios, a abertura de um processo de investigação contra empresas estrangeiras.

Além disso, a polêmica emenda Byrd, sancionada por Clinton às vésperas das últimas eleições presidenciais nos Estados Unidos, determina que o dinheiro obtido pelo governo norte-americano com a cobrança de taxas antidumping será destinado às empresas que abriram a denúncia e venceram o caso, o que evidentemente se constitui num incentivo adicional para as companhias norteamericanas abrirem mais processos antidumping contra competidores estrangeiros. Não é para menos que, dos atuais 1.121 casos de medidas antidumping em vigor, 300 foram aplicados pelos EUA.

Cabe ainda assinalar que um dos mais importantes acordos assinados por ocasião da criação da OMC, o Trips, sigla em inglês do Acordo de Propriedade Intelectual relacionada ao Comércio, beneficiou largamente os países desenvolvidos em detrimento dos países em desenvolvimento. O próprio Banco Mundial recomendou recentemente, no relatório Perspectivas da Economia Mundial em 2001, um novo equilíbrio no acordo para permitir aos países em desenvolvimento, principalmente os mais pobres, $o$ acesso a remédios e produtos essenciais ao desenvolvimento a preços competitivos (Chade, 01/11/01).

O estudo afirma que, na situação atual, se os países em desenvolvimento tivessem que implementar totalmente o Acordo sobre Propriedade Intelectual - Trips, teriam que pagar US\$ 20 bilhões a companhias no exterior por direitos de propriedade intelectual. Segundo o banco, a introdução desse tratado beneficiou principalmente os Estados Unidos que, como sede de numerosas companhias detentoras de patentes, obtiveram uma renda adicional líquida de US\$19,1 bilhões por ano. A Alemanha teve um ganho de US\$ 6,7 bilhões por ano. No sentido oposto, a Coréia do Sul é o país com a maior transferência de recursos por causa da importação líquida de tecnologia a um custo de US\$15,3 bilhões por ano. Outro país em desenvolvimento que paga alto pelo estoque de patentes é a China, com US\$ 5,1 bilhões. O Brasil paga ao exterior US\$ $530 \mathrm{mi}-$ lhões (Moreira, 01/11/01).

Até mesmo em tradicionais redutos do liberalismo econômico o direito irrestrito sobre a propriedade intelectual vem sendo questionado. Em matéria publicada na edição de 14 de abril último, a revista inglesa The Economist afirma que a propriedade do conhecimento não pode ser colocada no mesmo pé de igualdade que a propriedade de bens materiais, tangíveis. Isto porque, enquanto o consumo de um bem tangível por uma pessoa impede o consumo de outra (se eu uso um par de sapatos ninguém poderá usá-lo simultaneamente), tal não ocorre com o conhecimento, que pode ser partilhado, sem que ninguém fique privado de seu uso.

Um dos mais renomados defensores do livre-comércio internacional, o professor da Universidade de Columbia, Jagdish Bhagwati, considera um absurdo a ênfase que a Organização Mundial do Comércio - OMC vem dando à questão da propriedade intelectual. Para ele, a proteção à propriedade intelectual que a OMC e os Estados Unidos defendem tão ardorosamente não passa de um imposto que os países pobres pagam para usar o conhecimento dos ricos, portanto, uma transferência para as nações industrializadas.

Tudo isso revela como foi inoportuna, precipitada e subserviente a decisão brasileira em aceitar passivamente, em 1994, a nova lei de patentes imposta pela OMC, sob pressão dos Estados Unidos e dos laboratórios multinacionais de medicamentos, inclusive com excrescências como o mecanismo (chamado em inglês de pipe-line), que permitiu que as patentes fossem estendidas até para produtos que haviam sido inventados antes da aprovação da lei, como é o caso dos remédios anti-aids que compõem os atuais coquetéis.

Países como a Índia, que se recusaram a aceitar as imposições das multinacionais, estão produzindo tais medicamentos a um custo que chega a ser 30 vezes inferior ao cobrado pelas mutinacionais. Além disso, disputam com suas empresas locais (Cipla e Hetero) um mercado de alta tecnologia, como o de fármacos, e ainda se constituem na esperança de milhões de doentes no mundo que, não fossem essas empresas, dificilmente teriam acesso a medicamentos a preços razoáveis.

De maneira geral, é possível considerar que os resultados da Rodada Uruguai e a criação da OMC trouxeram mais benefícios para as economias desenvolvidas do que para os 
países em desenvolvimento. Segundo o estudo do FMI intitulado "Acesso ao Mercado de Exportações dos Países em Desenvolvimento" até 2005, ano em que, em tese, todas as barreiras ao comércio negociadas durante a Rodada Uruguai deverão ser eliminadas, os países industrializados contabilizarão um ganho total de US\$ 146,2 bilhões em função da liberalização ocorrida a partir de 1995. O ganho dos países em desenvolvimento será menor: US\$ 108,1 bilhões.

\section{OMC, ALCA E MERCOSUL}

O Brasil encontra-se atualmente numa verdadeira encruzilhada histórica no que diz respeito às suas relações internacionais de comércio. Foram negociados, simultaneamente: a manutenção do Mercosul, fortemente ameaçado pela crise da Argentina e pelas dificuldades de compatibilização dos regimes cambiais do Brasil e da Argentina; o acordo de livre-comércio entre o Mercosul e a União Européia; a formação da Área de Livre Comércio das Américas - Alca; e a pauta da próxima rodada de negociações comerciais da OMC. Das quatro, a manutenção do Mercosul e as negociações no âmbito da OMC são as mais importantes, vindo em terceiro lugar o acordo de livre-comércio com a União Européia e, por último, as negociações da Alca.

A prioridade máxima ao Mercosul justifica-se pelo fato de que este bloco comercial tem importância estratégica para o Brasil e, com mais razão, para os demais parceiros do bloco. Isoladamente, o Brasil - e muito menos Argentina, Paraguai ou Uruguai - teria as mínimas chances de garantir a efetiva inclusão, nas outras três negociações em curso, dos problemas que consideram mais relevantes na pauta de negociações. Mesmo que para a manutenção do bloco seja necessário promover recuos temporários no que diz respeito à construção da união aduaneira e do mercado comum, a sua manutenção tem um sentido estratégico.

A importância, para o Brasil, das negociações no âmbito da OMC também é evidente. A manutenção de um sistema multilateral de comércio aberto é o quadro institucional que mais nos convém, dado que nossas relações comerciais não estão concentradas com nenhum bloco comercial ou país em particular. Além disso, há uma série de questões relevantes de interesse para o Brasil, como a eliminação dos subsídios agrícolas, das cotas de importação e do uso abusivo das medidas antidumping por parte dos países desenvolvidos que dificilmente poderiam ser negociadas apenas no âmbito bilateral.

Como lembra Mark Jank, um dos maiores especialistas brasileiros em política comercial agrícola, esses temas dificilmente serão eliminados no âmbito das Américas (Alca) e mesmo no futuro acordo entre Mercosul e União Européia, mesmo porque, como afirma "EUA e Europa só pretendem discutir esses temas na esfera multilateral" (Puliti, 18/08/01). Além disso, em que pese o fato de as regras da OMC favorecerem claramente as economias desenvolvidas, como visto anteriormente, ainda assim, a existência de um fórum multilateral para discussão das questões comerciais é melhor para os países em desenvolvimento do que ficar à mercê de negociações bilaterais com as grandes potências comerciais.

Para economias emergentes, como a do Brasil, negociações multilaterais são importantes por dois motivos: permitem maior equilíbrio na composição de interesses e tornam mais equitativa a solução de conflitos. Em estudo recente, Vera Thorstensen, assessora econômica da missão brasileira na $\mathrm{OMC}$, afirma que o Brasil saiu-se bem em $85 \%$ das disputas que enfrentou na Organização Mundial do Comércio - OMC (Moreira, 01/11/01).

A terceira prioridade deveria ser costurar um acordo de livre-comércio com a União Européia. Além de significar um enorme fortalecimento do Mercosul, que firmar-se-ia definitivamente como pólo aglutinador da América do Sul, contribuindo sem dúvida, para a futura formação da Área de Livre Comércio da América do Sul (Amercosul), permitiria ao país conduzir as negociações da Alca em condições muito mais favoráveis. Além disso, é importante lembrar que o Brasil tem na UE seu maior mercado de exportação.

Finalmente, deveriam vir as negociações da Área de Livre Comércio das Américas - Alca. Muito embora e até porque de todas as negociações em curso a Alca é sem dúvida a que produziria maiores impactos, negativos ou positivos, sobre a economia brasileira, sua negociação deve ser cautelosa e sujeita a uma série de pré-condições.

Destaque-se, em primeiro lugar, que aderir de forma precipitada à Alca significa assumir, definitivamente, a condição de peão dos Estados Unidos no tabuleiro de xadrez das relações internacionais. Assim como o México é hoje um mero apêndice da economia americana, dificilmente o Brasil obteria um estatuto superior a este, caso aderisse à Alca nas condições atualmente estabelecidas pelos Estados Unidos.

Além do mais, se for negociada a adesão à Alca antes de serem consolidados plenamente o Mercosul e o acordo de livre-comércio com a União Européia, fazê-lo depois será uma tarefa quase impossível, seja pela perda de status e provável diluição do Mercosul na Alca, seja porque eventuais acordos tornar-se-iam muito mais complicados. É preciso considerar ainda que, no quadro atual 
das negociações, os Estados Unidos não têm se mostrado nem um pouco dispostos a abrir mão de sua política comercial protecionista para viabilizar o acordo.

Nessas condições, até Joseph Stiglitz, ex-economista chefe do Banco Mundial e ganhador do prêmio Nobel de economia em 2001, não tem dúvidas em aconselhar os países da América Latina a não embarcar na Área de Livre Comércio das Américas, se os Estados Unidos não reduzirem ou eliminarem barreiras e programas como os de apoio à produção de commodities agrícolas.

Falando à agência Inter Press Service durante viagem ao Equador, Stiglitz foi taxativo: sem concessões dos Estados Unidos, a Alca "não beneficiará as economias da América Latina e do Caribe e, em vez disso, prolongará uma relação desigual" (Sotero, 31/10/01). Fatos pouco animadores, como o recente pronunciamento da Comissão de Comércio Internacional (ITC) dos EUA a propósito das importações de aço do Brasil, tachando-se de danosas à siderúrgica norte-americana, não autorizam perspectivas otimistas quanto à disposição norte-americana de abrir mão das políticas protecionistas que utilizam sempre que lhes convêm.

Finalmente, mas não menos importante, é preciso levar em conta que uma eventual adesão do Brasil à Alca sem maiores cuidados poderia significar a liquidação de grande parte do parque industrial brasileiro. Estudo recente da Fiesp mostra que, com exceção de aviação, siderurgia e químicos, as demais cadeias de produção têm defasagem em relação às dos EUA em aspectos fundamentais e que empresas nacionais de inúmeros setores teriam dificuldades para brigar no livre-comércio (Pereira, 24/09/01).

Ao se considerar que, atualmente, a futura Alca representa, para o Brasil, 70\% das exportações de manufaturados, uma adesão precipitada poderia significar a degradação definitiva de nossa pauta de exportações.

\section{NOTAS}

1. A Alemanha é, atualmente, o principal destino das exportações brasileiras de café, à frente inclusive dos Estados Unidos, que durante muitos anos foram nosso principal mercado. Entre janeiro e agosto de 2001 as exportações brasileiras de café verde para a Alemanha foram de 2,2 milhões de sacas ou $18 \%$ do volume exportado. O mercado italiano passou para o segundo lugar, no mesmo nível dos Estados Unidos, com $11 \%$.

\section{REFERÊNCIAS BIBLIOGRÁFICAS}

ABBOTT, M.L. "OMC observa aumento de subsídios". Gazeta Mercantil. São Paulo, 24/11/2000, p.A11.
CANUTO, O. "O economista da lamparina e a ponte". O Estado de S.Paulo. São Paulo, 16/10/2001, p.B2.

CARVALHO, R. de D. "Cresce participação do café brasileiro no exterior”. Gazeta Mercantil. São Paulo, 01/11/2001, p.B14.

CASTILHO, M.R. "O acesso das exportações do Mercosul ao mercado Europeu" <www.anpec.org.br>.

CASTRO, G. "Brasil atrai mais investimentos diretos". Gazeta Mercantil Latino-Americana. São Paulo, 15 a 21/outubro/2001, p.16.

CHADE, J. "Brasil deve ir à OMC contra subsídio americano". O Estado de S.Paulo. São Paulo, 24/07/2001, p.B12.

"Relatório do Banco Mundial sugere revisão da lei de patentes". O Estado de S.Paulo. São Paulo, 01/11/2001, p.A11.

DRAIBE, S. Rumos e metamorfoses. São Paulo, Paz e Terra, 1985.

FOLHA DE S.PAULO. "Brasil analisa acordo de fluxo de capitais". São Paulo, 07/07/1997, p.2-7.

GAZETA MERCANTIL. "Distender o comércio internacional". São Paulo, 23/05/2001, p.A2. p.A2.

“Derrubar as barreiras ao açúcar". São Paulo, 13/08/2001,

GRINBAUM, R. "País exporta agrícolas a preço de fim de feira". Folha de S.Paulo. São Paulo, 21/10/2001, p.B4.

HAMILTON, A. Relatório sobre manufaturas. Rio de Janeiro, Solidariedade Ibero-americana, 1995.

KUPFER, J.P. "Números do hiato tecnológico". Gazeta Mercantil. São Paulo, 17/10/2001, p.A3.

LACERDA, A.C. de. "A nova dinâmica da economia global". Gazeta Mercantil. São Paulo, 17/05/2001.

"Por que faz falta um projeto nacional?". Gazeta Mercantil. São Paulo, 18/06/2001.

"Uma nova agenda para o desenvolvimento global". $G a$ zeta Mercantil. São Paulo, 05/10/2001, p.A3.

MAGALHÃES, A. d'A. "Desindustrialização na agroindústria". $G a-$ zeta Mercantil. São Paulo, 05/09/1991.

MAGGI, B.; LOVATELLI, C. e RODRIGUES, R. "Escalada tarifária na soja brasileira". Gazeta Mercantil. São Paulo, 11/06/2001.

MAGGI, B.B. "A agricultura e o império do medo". Gazeta Mercantil. São Paulo, 01/11/2001, p.A3.

MAGNAVITA, M. "Cresce saldo negativo na balança dos eletrônicos". Gazeta Mercantil. São Paulo, 19/06/2001.

MARQUES Jr., L. "Múltis sofrem para cumprir legislação no Brasil". Gazeta Mercantil. São Paulo, 30/10/2001, p.A3.

MOREIRA, A. "Brasil propõe revisão do acordo antidumping". Gazeta Mercantil. São Paulo, 31/05/2001.

"Novas regras na OMC". Gazeta Mercantil. São Paulo, 29/08/2001.

“"As duras negociações na OMC”. Gazeta Mercantil. São Paulo, 01/11/2001, p.A6.

"Bird sugere acesso mais fácil a produto essencial". $\mathrm{Ga}$ zeta Mercantil. São Paulo, 01/11/2001, p.A6.

"Brasil quer acordo têxtil com a União Européia". Gazeta Mercantil. São Paulo, 01/11/2001, p.A6.

"País tem bom desempenho na OMC". Gazeta Mercantil. São Paulo, 01/11/2001, p.A7.

NASSIF, L. "O protecionismo americano". Folha de S.Paulo. São Paulo, 05/10/2001, p.B3. 
O ESTADO DE S.PAULO. "Livre comércio só na conversa”. São Paulo, 05/10/2001, p.A3.

. "Câmara dos EUA aprova subsídio a produtores". São Paulo, 24/10/2001, p.B10.

PEREIRA, P. "Estudo define áreas de proteção no cenário da Alca". Gazeta Mercantil. São Paulo, 24/09/2001, p.A8.

PRADO, S. "A dura tarefa de abrir o leque de exportações". Gazeta Mercantil. São Paulo, 09/07/2001.

PULITI, P. "Só OMC ajudaria a disciplinar subsídios". O Estado de S.Paulo. São Paulo, 18/08/2001, p.B12.

RACY, S. e OLIVEIRA, E.M. "Entrevista - Não produzimos o que o mundo quer comprar". O Estado de S.Paulo. São Paulo, 02/09/2001, p.B12.

ROMERO, C. "Subsídios aumentam 400\% nos EUA". Valor. São Paulo, 23/05/2001, p.A12.

ROSSI, C. "Só $18 \%$ das exportações do país são "ótimas". Folha de S.Paulo. São Paulo, 03/06/2001, p.B10. 2001, p.A2.

"De 35 a 10 mil". Folha de S.Paulo. São Paulo, 21/10/

ALGADO, E. "Receita para crescer - Entrevista: Jeffrey Sachs". Revista Veja. São Paulo, Ed. Abril, 18/07/2001.

SOTERO, P. "Prêmio Nobel alerta para concessões na Alca". O Estado de S.Paulo. São Paulo, 31/10/2001, p.B4.

STEINBRUCH, B. "Exportando grama". Folha de S.Paulo. São Paulo, 11/07/2000, p.B2.

. "Exportar ou morrer! É para valer?". Folha de S.Paulo. São Paulo, 30/10/2001, p.B2.

VARGAS, L. "EUA vão ampliar protecionismo ao aço". O Estado de S.Paulo. São Paulo, 23/10/2001, p.B4.

Luís Antônio Paulino: Engenheiro e Analista da Fundação Seade (lpaulino@seade.gov.br). 